\title{
Identification of colorectal cancers with defective DNA damage repair by immunohistochemical profiling of mismatch repair proteins, CDX2 and BRCA1
}

\author{
SAVITHA RAJARAJAN ${ }^{1}$, ANUPAMA C.E ${ }^{1}$, BETSY JOSE ${ }^{2}$, MARJORIE CORREA ${ }^{2}$, \\ SAGAR SENGUPTA ${ }^{3}$ and JYOTHI S. PRABHU ${ }^{1}$ \\ ${ }^{1}$ Division of Molecular Medicine, St. John's Research Institute and ${ }^{2}$ Department of Pathology, \\ St. John's Medical College, Bangalore 560034; ${ }^{3}$ National Institute of Immunology, New Delhi 110067, India
}

Received January 27, 2020; Accepted July 9, 2020

DOI: $10.3892 / \mathrm{mco} .2020 .2128$

\begin{abstract}
Colorectal cancer (CRC) is a complex disease as shown by consensus classification. The present study attempted to identify subtypes with known prognostic markers for better clinical management. A total of $72 \mathrm{CRC}$ tumors were examined for the expression of mismatch repair (MMR) proteins, along with caudal-type homeobox protein 2 (CDX2) and BRCA1, by immunohistochemistry. Tumors were assigned based on the presence or loss of MMR proteins as proficient or deficient. Correlations were examined with CDX2 and BRCA1 along with clinico-pathological features. Expressional pattern of microRNAs (miRs/miRNAs), such as miR-183-96-182, known to be associated with defective DNA damage repair were evaluated by reverse transcription-quantitative PCR. A total of $22 \%$ of the CRC tumors were assigned as deficient in mismatch repair. $71 \%$ of the tumors expressed CDX2 while only $21 \%$ had nuclear expression of BRCA1. Loss of CDX2 protein was higher in the deficient subtype compared with the proficient subtype. A total of $14 \%$ of the tumors had dual loss of MMR and BRCA1 proteins and showed aggressive clinical features in addition to elevated expression of DNA damage repair microRNAs. The present study shows the presence of a small proportion of colorectal tumors with dual loss of key proteins involved in DNA damage repair which may be amenable to specific therapy. The implication of the present observations warrants investigation in a larger patient cohort with prognostic information.
\end{abstract}

Correspondence to: Dr Jyothi S. Prabhu, Division of Molecular Medicine, St. John's Research Institute, St. John's Medical College, Koramangala 100 Ft Road, Bangalore 560034, India

E-mail: jyothi@sjri.res.in

Key words: colorectal cancer, mismatch repair proteins, BRCA1, caudal-type homeobox protein 2, DNA damage repair, microRNA

\section{Introduction}

With 1.8 million new cases and almost 861,000 deaths in 2018 globally, colorectal cancer (CRC) is the third most commonly diagnosed cancer in males and the second in females according to the World Health Organization (1). Improvements in earlier cancer detection and management, in combination with an increased understanding of the molecular and genetic basis of the disease will aid in better treatment decision and may also guide future therapeutic approaches (2).

The microsatellite instability (MSI) pathway is amongst the most important molecular pathways identified to cause $\mathrm{CRC}$, along with other pathways, such as the chromosomal instability, $\mathrm{CpG}$ island methylator phenotype and serrated pathways (3). MSI is the accumulation of repeat length mutations in short DNA sequences and arises from defects in the DNA mismatch repair (MMR) system, which corrects any errors made by DNA polymerases during DNA replication (4). Tumours with MSI have a better prognosis than microsatellite stable CRC (5). Detection of MSI status performed using PCR-based methods or deficiency status of MMR proteins, including DNA mismatch repair protein Mlh1 (MLH1), DNA mismatch repair protein Msh2 (MSH2), DNA mismatch repair protein Msh6 (MSH6) and mismatch repair endonuclease PMS2 (PMS2), detected using immunohistochemistry (IHC) is routinely advocated to detect hereditary cancer, such as in Lynch syndrome, and also to predict the prognosis/chemotherapy response including the response to most recent immunotherapies (6).

CRC is known to be a heterogenous disease characterized by different molecular subtypes. Consensus molecular subtyping is most beneficial in the identification of a specific targeted therapy for both initial treatments and in metastatic settings (7-9). Similar attempts to classify CRC have been made by evaluating multiple markers, such as caudal-type homeobox protein 2 (CDX2), BRCA1, p53, adenomatous polyposis coli, $\beta$-catenin and other DNA repair proteins such as MMR proteins, $\mathrm{O}^{6}$-methylguanine DNA methyltransferase and excision repair cross-complementing 1 , and correlate them with survival and response to therapy (10). CDX2 has been well-established as a diagnostic marker for CRC and 
its downregulation is associated with poor differentiation and MMR deficiency (11). However, less is known about the utility of BRCA1 in CRC, except in a few studies where the expression of BRCA1 predicting a better survival rate has been reported $(12,13)$. The role of BRCA1 as a tumour suppressor gene was confirmed by its action in DNA damage repair (DDR), mediated mainly via homologous recombination-based pathways (14). Apart from mutations, epigenetic mechanisms, such as those mediated by miRNAs, are also known to mediate loss of BRCA1 function (15). miRNAs are small noncoding RNAs of 19-22 base pairs that are generated by a series of enzymatic processes in the nucleus and cytoplasm. Apart from affecting multiple cellular processes, several miRs, such as miR-16, miR-24, miR-188 and the miR-183-96-182 cluster have been implicated in DNA damage response and DNA repair $(16,17)$. Defects in DDR drive cancer development by fostering DNA mutations, but also provide cancer-specific vulnerabilities that can be therapeutically exploited. The recent approval and use of multiple newer modalities of cancer therapy, such as using poly ADP ribose polymerase inhibitors through the approach of synthetic lethality, or checkpoint inhibitors and immunomodulatory drugs, have made them promising candidates for the treatment of multiple types of cancers (18-20).

Although the incidence of CRC in India is much lower than in the West, a higher proportion of right sided and grade III tumours has been reported and is associated with significant mortality and morbidity (21). With an interest to evaluate and correlate clinical features with known prognostic markers, the present study was performed on a retrospective series from the pathology archives. The present study analysed the association between MMR proteins, CDX2 and BRCA1 to determine the utility of their inter-relationship in the identification of subclasses amenable to specific therapies.

\section{Materials and methods}

Selection of primary colorectal cancer samples. Seventy-six colorectal cancer tumour blocks were identified and selected for the study. These cases were examined and reported by the Department of Pathology, St. John's Medical College and Hospital, Bangalore, India between 2013 and 2017. The present retrospective study was approved by the Institutional Ethical Committee, St John's Medical College and Hospital. Representative formalin-fixed and paraffin-embedded tumour blocks from each of the selected cases were obtained for the study. All tumours with a $>50 \%$ tumour content, as estimated by a pathologist from the consecutive series, were chosen for analysis. Clinico-pathological characteristics, such as age, sex, grade, pathological and lymph node stage, histological type, lymphocytic response, lymphovascular invasion and tumour site were obtained from the clinical and histopathological records from the hospital.

Tissue microarray (TMA) construction and IHC of CDX2, BRCA1 and mismatch repair proteins MSH2, MSH6, MLH1 and PMS2. TMA was constructed using the Quick Ray manual tissue microarrayer (Unitma Co., Ltd.). A master block grid plan was made with adequate precautions to ensure an accurate orientation and unambiguous specimen identification. Block construction was performed according to the manufacturer's instructions. Two cores of $1.5 \mathrm{~mm}$ each were taken from each tumour block. Sections were cut and stained with hematoxylin and eosin (H\&E) to confirm the adequate representation of each tumour. Cores with $<100$ interpretable tumour cells were excluded from the analysis.

IHC was performed for CDX2, BRCA1 and MMR proteins (MLH1, PMS2, MSH2 and MSH6), according to standard procedures. Briefly, $5-\mu \mathrm{m}$ thick sections were placed on poly-L-lysine-coated slides and subjected to deparaffinization in xylene and rehydrated in graded alcohol. Following blocking endogenous peroxidase with a $3 \%$ hydrogen peroxide solution, antigen retrieval was performed in $0.01 \mathrm{~mol} / 1$ EDTA buffer at $\mathrm{pH} 8$ using a heat triggered multi-epitope retrieval system (PathnSitu Biotechnologies Pvt. Ltd.) for $15 \mathrm{~min}$ at $90^{\circ} \mathrm{C}$. Primary blocking was done with $1 \%$ BSA (Sigma-Aldrich; Merck KGaA) for $30 \mathrm{~min}$ at room temperature. Details of the primary antibody clone, source and the dilutions are shown in Table SI. Primary antibodies were applied for $1 \mathrm{~h}$ at room temperature. Sections were further incubated with secondary antibody (cat. no. K5007; EnVision Detection System; Dako; Agilent Technologies, Inc.) for $20 \mathrm{~min}$ as per the kit instructions, followed by colour development using 3, 3-diaminobenzidine for $10 \mathrm{~min}$. Sections were counterstained with haematoxylin for $5 \mathrm{~min}$ at room temperature and mounted after dehydration in graded alcohol and xylene. Appropriate positive and negative controls were run for each batch.

Evaluation of CDX2, BRCA1 and MMR proteins. For CDX2 and BRCA1 scoring, each tumour core was scored for intensity as follows: $0=$ no staining; $1=$ weak staining; $2=$ moderate staining; $3=$ strong staining. The percentage of cells stained was estimated from $0-100 \%$. The histochemical score (H score range, 0-300) was calculated by multiplying the intensity and the percentage of staining. Although BRCA1 staining was observed in both the nucleus and the cytoplasm, only its nuclear presence was evaluated, indicating BRCA1 functional ability. A nuclear $\mathrm{H}$ score of $\geq 10$ was considered as positive BRCA1 and CDX2 expression. The $\mathrm{H}$ score was used for the analysis of both proteins to obtain a quantitative estimate with a broad dynamic range from 0-300 (22). In the absence of any standard diagnostic criteria for proteins such as BRCA1 and CDX2, the H score method was followed for quantitation.

MMR proteins were scored only on the percentage of stained tumour cells, irrespective of staining intensity. Standard guidelines were followed where any presence of MMR proteins in the nucleus is considered adequate and acceptable to record as intact expression (23). Intact normal staining of non-tumour cells was considered as an internal positive control. Cases with $\geq 10 \%$ tumour cells showing nuclear staining were considered positive (intact expression). Weak focal nuclear stain in $<10 \%$ of tumour cells was considered focal expression and a complete absence of nuclear stain in the presence of the positive internal control (lymphocytes and stromal cells) was considered negative (loss of expression). The dual loss of either MSH2 and MSH6 or MLH1 and PMS2, or the isolated loss of PMS2 was considered as an MMR-deficient group (dMMR). Intact/focal protein presence of either MSH2/MSH6 or MLH1/PMS2 was considered as an MMR-proficient group (pMMR). 
H\&E-stained microscopic sections of tumors were simultaneously evaluated by two trained pathologists to confirm the presence of above proteins in the tumor cells in comparison to normal cells (24). Each tissue microarray core was examined microscopically by the same pathologists independently to count $\sim 1,500$ cells in three different areas on the tissue section. The mean expression levels of both the observers were taken as final scores. In case of disagreement, the final score was determined by consensus after re-examination.

$R N A$ extraction and reverse transcription-quantitative $P C R$ (RT-qPCR) of miRNAs. The methods used for nucleic acid extraction and RT-qPCR have been described in detail in our previous publication (25). In brief, two $20-\mu \mathrm{m}$ sections taken from each patient's tumour block were deparaffinized using heat, and then subjected to overnight digestion using proteinase K (cat. no. 19133; Qiagen GmbH). Total RNA was then extracted using TRI reagent according to manufacturer's instructions (cat. no. T9424; Sigma-Aldrich; Merck KGaA). RNA quantification was performed using the Qubit RNA BR Assay kit (cat. no. Q10210; Invitrogen; Thermo Fisher Scientific, Inc.) on a Qubit 2.0 Fluorometer (cat. no. Q32866; Invitrogen; Thermo Fisher Scientific, Inc). Samples with a yield of $\geq 500 \mathrm{ng}$ RNA and adequate transcript preservation to show amplification by RT-qPCR were used for subsequent experiments.

miRNA present in total RNA extracted as described above was converted to cDNA using stem-loop primers specific for the chosen $\mathrm{miR}$, according to published protocols. Detailed methodology for quantification of miR using qPCR is provided in our previous publication (26). Briefly, $50 \mathrm{ng}$ of total RNA was used for cDNA conversion using the TaqMan microRNA Reverse Transcription kit (cat. no. 4366596; Applied Biosystems; Thermo Fisher Scientific, Inc.). The expression levels of a selected set of DDR miRs (miR183, miR96 and miR182) were determined, along with the control miR (RNU48). The assay IDs (cat. no. 4427975; Applied Biosystems; Thermo Fisher Scientific, Inc,) and sequences of the miRs are shown in Tables SII and SIII. Cycle threshold $(\mathrm{Ct})$ values for the test miRs were normalized relative to the mean $\mathrm{Ct}$ value of the control miR for each sample as $\Delta \mathrm{Ct}$. The relative normalized units of expression of the test miRs were calculated as $15-\Delta \mathrm{Ct}$, representing the dynamic range of the assay as being $15 \mathrm{Cts}$.

Statistical analysis. Descriptive analysis was used to tabulate the clinical variables amongst the various groups segregated based on the presence or absence of the chosen protein markers. All markers were expressed as the proportion of cases noted as positive or negative. Parametric or non-parametric tests of significance, such as paired Student's t-test or the Mann Whitney $U$ test, based on the normality of distribution, were applied to determine the levels of significance in the distribution of chosen variables between the groups. The correlation between protein expression levels was calculated using Pearson's correlation coefficient. In the absence of prior available data for combined loss of BRCA1 and MMR proteins, sample size estimates were not attempted. Analysis was performed on XLStat software (version 2019.4.2; Addinsoft). $\mathrm{P}<0.05$ was considered to indicate a statistically significant difference.

\section{Results}

Clinical characteristics of the cohort. The mean and median age of the CRC patients was 54.9 and 55 years, respectively. Of the 76 tumours studied, two were uninterpretable in CDX2 and BRCA1 IHC, one tumour yielded insufficient RNA and one tumour had loss of all MMR proteins, and therefore, only $72(95 \%)$ tumours could be satisfactorily interpreted. A slight male preponderance was noted with $58 \%$ (42/72) in the group of tumours selected. The right and left sided tumours were equal in ratio. Most tumours belonged to stage II (38\%) and stage III (43\%). Details on the tumour grade were available for $70 \%(51 / 72)$ of tumours, and most (84\%) of them were grade II tumours. Approximately $40 \%$ (29/72) of the tumours had a high lymphocytic response and lympho-vascular invasion was present in $43 \%$ (31/72) of tumours.

Of the 36 right sided tumors, 12 (33\%) were mucinous tumors. The presence of the CDX2, BRCA1 proteins and the MMR status were further examined among mucinous and non-mucinous tumours. No statistically significant difference was observed between the two groups (data not shown).

Staining pattern and distribution of all proteins. CDX2 is known to be widely expressed in the large intestine (11) and showed nuclear staining with bright intensity. BRCA1 staining intensity was lower compared with CDX2 expression and varied across tumours. The intensity of MMR protein staining also varied widely.

Expression of MMR proteins. Among the four MMR proteins studied, MSH2 and PMS2 had intact/focal expression in $89 \%$ of the tumours. Table I details the expression levels of all the MMR proteins. MLH1 protein was detected in a small proportion of tumours (42\%). MSH6 was always intact $(60 \%)$ in the presence of MSH2, while the presence of PMS2 was observed in 34/42 tumours when MLH1 was absent. Tumours with the dual loss of MSH2 and MSH6 (11\%) had intact protein status for either MLH1 and/or PMS2, and vice versa (10\%). The dual presence of MLH1 and PMS2 was observed in 29\% of the tumours, while only one tumour had isolated loss of PMS2. A total of $22 \%(16 / 72)$ of the tumours were categorized as dMMR, as they had a dual loss of MSH2/MSH6 or MLH1/ PMS2, or the isolated loss of PMS2. Representative microscopic IHC images of all the MMR proteins showing positive nuclear stain are shown in Fig. 1A-D. As shown in Fig. 1, MLH1 presented with the lowest staining intensity compared to other MMR proteins. Table II shows the association of MMR status with clinical variables. None of the clinical variables were significantly different between the MMR proficient and deficient subtypes, aside from dMMR tumours, which had a higher lymph node spread (P-0.02). Among the dMMR tumours, $75 \%$ of them belonged to males and almost $70 \%$ of them belonged to stage III, although this was not statistically significant.

CDX2 and BRCA1 expression. An intense nuclear staining of CDX2 protein in $>10 \%$ of the tumour nuclei was considered positive and observed in $71 \%(51 / 72)$ of tumours (Fig. 1E; $\mathrm{H}$ score, 100x3-300). Clinical variables, such as age, sex, grade or stage did not differ between CDX2-positive and -negative 
Table I. Distribution of MMR protein expression in colorectal tumours.

\begin{tabular}{lccr}
\hline IHC marker & Loss of expression & Intact expression & Focal expression \\
\hline MLH1 & $42(58)$ & $22(31)$ & $8(11)$ \\
PMS2 & $8(11)$ & $49(68)$ & $15(21)$ \\
MSH2 & $8(11)$ & $57(79)$ & $7(10)$ \\
MSH6 & $29(40)$ & $30(42)$ & $13(18)$ \\
MLH1 and PMS2 dual loss & $7(10)$ & - & - \\
MSH2 andMSH6 dual loss & $8(11)$ & - & - \\
Isolated PMS2 loss & $1(1)$ & - & - \\
dMMR & $16(22)$ & - & - \\
pMMR & $56(78)$ & - \\
\hline
\end{tabular}

Data are presented as n (\%). MMR, mismatch repair; dMMR, MMR deficient; pMMR, MMR proficient; MSH2, DNA mismatch repair protein Msh2; MSH6, DNA mismatch repair protein Msh6; MLH1, DNA mismatch repair protein Mlh1; PMS2, mismatch repair endonuclease PMS2.

A

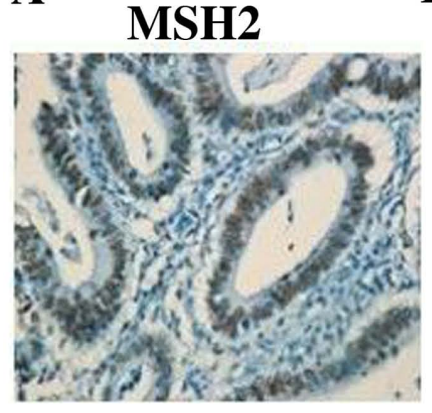

B

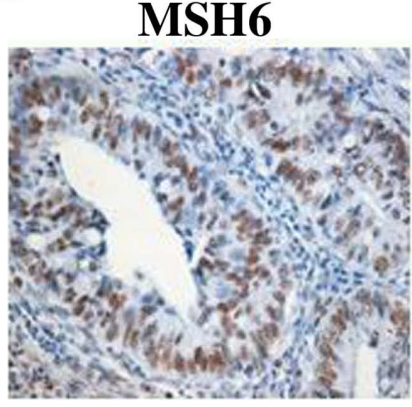

C

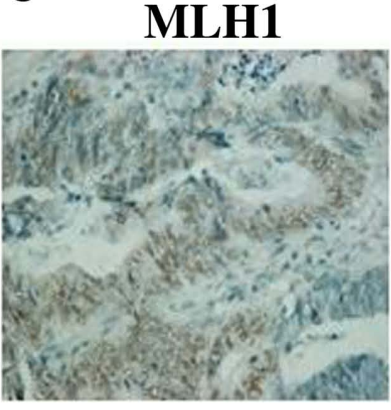

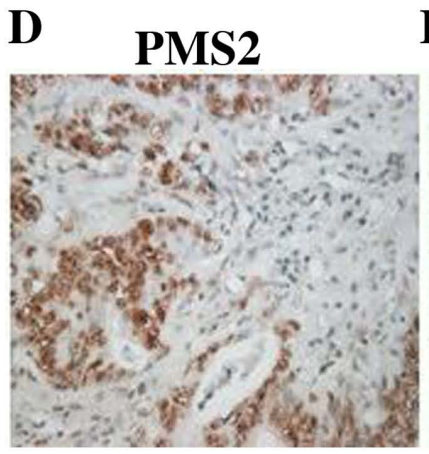
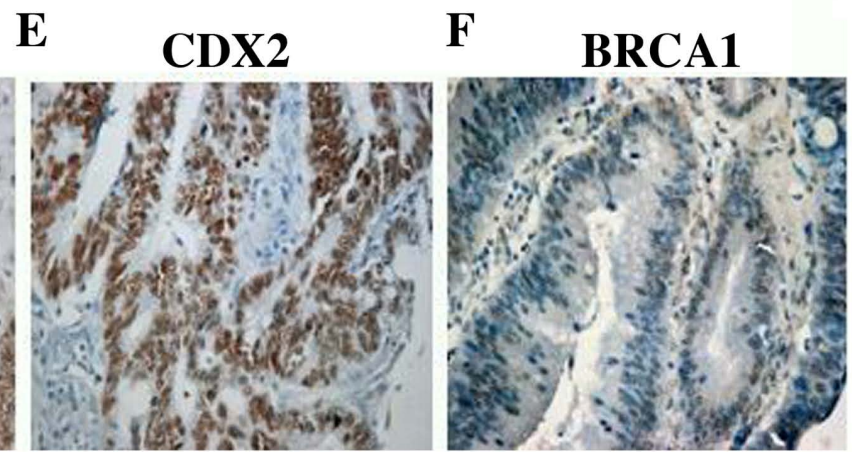

Figure 1. Representative microscopic images of MMR proteins, CDX2 and BRCA1. Nuclear staining of MMR proteins (A) MSH2, (B) MSH6, (C) MLH1 and (D) PMS2 in the presence of internal positive controls (lymphocytes and stromal cells). Nuclear staining of (E) CDX2 (H score, 100x3-300) and (F) BRCA1 (H score, 50x2-100) in tumour cells. Magnification, x20. MMR, mismatch repair; DNA mismatch repair protein Msh2; MSH6, DNA mismatch repair protein Msh6; MLH1, DNA mismatch repair protein Mlh1; PMS2, mismatch repair endonuclease PMS2; CDX2, caudal- type homeobox protein 2.

tumours (Table II), although a higher proportion of right sided tumours was CDX2-negative (62\% in right tumours vs. $45 \%$ in left tumours; P-0.2). Two-thirds (67\%) of the CDX2-negative tumours belonged to males and more than half of the CDX-positive tumours were lymph node-negative.

BRCA1 nuclear expression was observed in only $21 \%$ (15/72) of the tumour samples (Fig. 1F; H score, 50x2-100). Cytoplasmic expression of BRCA1 was observed in an additional $14 \%(10 / 72)$ of tumours; however, they were considered negative. No significant differences were seen for any clinical variables between BRCA1-positive or -negative tumours, although a higher proportion of BRCA1-positive tumours (60\%) was lymph-node negative (Table II).

Association of MMR proteins with CDX2 and BRCA1 expression. Association of CDX2 loss is often reported to be high in MMR-deficient tumours $(10,11)$. In the present study, 44\% (7/16) of dMMR tumours showed loss of CDX2, compared with $25 \%(14 / 56)$ observed in pMMR tumours (P-0.1). However, BRCA1 and MMR were inversely correlated, with $38 \%(6 / 16)$ of the dMMR group expressing BRCA1 protein, compared with only $16 \%(9 / 56)$ in the pMMR 
Table II. Distribution of CDX2, BRCA1 and MMR proteins amongst clinical variables.

\begin{tabular}{|c|c|c|c|c|c|c|}
\hline \multirow{2}{*}{$\begin{array}{l}\text { Marker } \\
\text { Staining }\end{array}$} & \multicolumn{2}{|c|}{$\mathrm{CDX} 2$} & \multicolumn{2}{|c|}{ BRCA1 } & \multicolumn{2}{|c|}{ MMR } \\
\hline & $\begin{array}{c}\text { Positive, } \\
\text { n-51 (71\%) }\end{array}$ & $\begin{array}{c}\text { Negative, } \\
\text { n-21 (29\%) }\end{array}$ & $\begin{array}{c}\text { Positive, } \\
\mathrm{n}-15(21 \%)\end{array}$ & $\begin{array}{c}\text { Negative, } \\
\text { n-57 (79\%) }\end{array}$ & $\begin{array}{l}\text { Proficient, } \\
\text { n-56 (78\%) }\end{array}$ & $\begin{array}{l}\text { Deficient, } \\
\text { n-16 (22\%) }\end{array}$ \\
\hline \multicolumn{7}{|l|}{ Variable } \\
\hline \multicolumn{7}{|l|}{ Age } \\
\hline Mean & 55.8 & 52.9 & 55.6 & 54.8 & 54.7 & 55.7 \\
\hline Median & 56 & 55 & 60 & 55 & 55 & 58 \\
\hline \multicolumn{7}{|l|}{ Sex } \\
\hline Male & $28(55)$ & $14(67)$ & $8(53)$ & $34(60)$ & $30(54)$ & $12(75)$ \\
\hline Female & $23(45)$ & $7(33)$ & $7(47)$ & $23(40)$ & $26(46)$ & $4(25)$ \\
\hline \multicolumn{7}{|l|}{ Tumor site } \\
\hline Right & $23(45)$ & $13(62)$ & $8(53)$ & $28(49)$ & $27(48)$ & $9(56)$ \\
\hline Left & $28(55)$ & $8(38)$ & $7(47)$ & $29(51)$ & $29(52)$ & $7(44)$ \\
\hline \multicolumn{7}{|l|}{ Grade } \\
\hline I & $2(5)$ & $1(10)$ & $0(0)$ & $3(7)$ & $2(5)$ & $1(10)$ \\
\hline II & $36(88)$ & $7(70)$ & $9(90)$ & $34(83)$ & $37(90)$ & $6(60)$ \\
\hline III & $3(7)$ & $2(20)$ & $1(10)$ & $4(10)$ & $2(5)$ & $3(30)$ \\
\hline \multicolumn{7}{|l|}{ LN status } \\
\hline N0 & $29(57)$ & $10(48)$ & $9(60)$ & $30(53)$ & $34(61)$ & $5(31)^{\mathrm{a}}$ \\
\hline N1 & $14(27)$ & 4 (19) & $4(27)$ & $14(25)$ & $14(25)$ & $4(25)$ \\
\hline $\mathrm{N} 2$ & $8(16)$ & $7(33)$ & $2(13)$ & $13(23)$ & $8(14)$ & $7(44)$ \\
\hline \multicolumn{7}{|l|}{ Stage } \\
\hline I & $7(14)$ & $3(14)$ & $2(13)$ & $8(14)$ & $8(14)$ & $2(13)$ \\
\hline II & $20(39)$ & 7 (33) & 7 (47) & $20(35)$ & $24(43)$ & 3 (19) \\
\hline III & $21(41)$ & $10(48)$ & $6(40)$ & $25(44)$ & $20(36)$ & $11(69)$ \\
\hline IV & $3(6)$ & $1(5)$ & $0(0)$ & $4(7)$ & $4(7)$ & $0(0)$ \\
\hline
\end{tabular}

Data are presented as $\mathrm{n}(\%) .{ }^{\mathrm{a} P}<0.05$, derived from paired two-tailed Student's t-test. LN status, lymph node status; MMR, mismatch repair; CDX2, caudal- type homeobox protein 2 .

subgroup (P-0.06).When the expressional pattern of BRCA1 and CDX2 were compared as $\mathrm{H}$ scores, a negative correlation was found between the two proteins (Pearson's correlation coefficient, -0.13; P-0.2), as expected.

Combined loss of BRCAl and MMR proteins show a higher expression of DDR miRNAs. Subsequently, the tumours were divided into two separate classes based on the dual presence and absence of BRCA1 and MMR status. While two-thirds of the tumours (53/72) showed either BRCA1 or MMR protein expression, only a small proportion of tumours $(12.5 \%)$ had the combined presence of both. A small subset $(10 / 72 ; 14 \%)$ of tumours was both BRCA1 negative and MMR deficient. When the clinical variables were compared between these groups (Table III), tumours with the combined loss of BRCA1 and MMR proteins showed aggressive features, such as a younger age, male preponderance and a higher proportion of grade III and stage III tumours. There was no difference in CDX2 expression between the two groups.

When the distribution of the miRs implicated in defective DDR (miR-183, miR-96 and miR-182) was examined in the two groups, tumours with the combined loss of BRCA1 and
MMR showed trends of higher expression of all the three miRs (P-0.01, miR-182), as shown in Table III, indicating defective pathways for DNA damage repair in these tumours.

\section{Discussion}

$\mathrm{CRC}$ is the most common malignancy in the western world and is associated with a significant morbidity. Among the different molecular pathways involved, although MSI contributes to less than one quarter of CRC cases, defects in MMR proteins have been implicated both in carcinogenesis and CRC progression (27). Although $90 \%$ of hereditary CRC present with MSI, it is limited to $15-20 \%$ of sporadic tumours (28). The present study showed that $22 \%$ of tumours presented with MMR deficiency, consistent with previously published studies (21,29). An earlier study on a cohort from a similar setting reported a deficient MMR prevalence of $22.9 \%$ (21). The present study observed loss of MLH1 protein in more than half of tumours of the cohort. Weaker staining patterns of MLH1, patchy and heterogenous staining pattern of MMR proteins, inactivation by promoter methylation and mutations are considered as multiple reasons for loss of MLH1 (30). The 
Table III. Comparison of clinical variables between tumors with dual loss of BRCA1 and MMR with other tumors.

\begin{tabular}{|c|c|c|c|}
\hline Variable & $\begin{array}{l}\text { Dual loss of BRCA1 } \\
\text { and MMR, n-10 (14\%) }\end{array}$ & Others $^{\mathrm{a}}, \mathrm{n}-62(86 \%)$ & P-value \\
\hline Age & & & NS \\
\hline Mean & 50.9 & 55.6 & \\
\hline Median & 50.5 & 55.5 & \\
\hline Sex & & & NS \\
\hline Male & $8(80)$ & $34(55)$ & \\
\hline Female & $2(20)$ & $28(45)$ & \\
\hline Tumor site & & & NS \\
\hline Right & $5(50)$ & $31(50)$ & \\
\hline Left & $5(50)$ & $31(50)$ & \\
\hline Grade & & & 0.072 \\
\hline I & $1(14)$ & $2(5)$ & \\
\hline II & $3(43)$ & $40(91)$ & \\
\hline III & $3(43)$ & $2(5)$ & \\
\hline LN status & & & $0.036^{\mathrm{b}}$ \\
\hline N0 & $3(30)$ & $36(58)$ & \\
\hline $\mathrm{N} 1$ & $2(20)$ & $16(26)$ & \\
\hline $\mathrm{N} 2$ & $5(50)$ & $10(16)$ & \\
\hline Stage & & & NS \\
\hline I & $2(20)$ & $8(13)$ & \\
\hline II & $1(10)$ & $26(42)$ & \\
\hline III & $7(70)$ & 24 (39) & \\
\hline IV & $0(0)$ & $4(6)$ & \\
\hline $\mathrm{CDX} 2$ & & & NS \\
\hline Positive & $4(40)$ & $17(27)$ & \\
\hline Negative & $6(60)$ & $45(73)$ & \\
\hline \multicolumn{4}{|l|}{ miR-183 } \\
\hline Mean & 8.3 & 7.7 & \\
\hline miR-182 & & & $0.01^{\mathrm{b}}$ \\
\hline Mean & 10.2 & 9.3 & \\
\hline \multicolumn{4}{|l|}{ miR-96 } \\
\hline Mean & 7.4 & 6.8 & \\
\hline
\end{tabular}

Data are presented as $\mathrm{n}(\%) .{ }^{\mathrm{a} O t h e r s, ~ B R C A 1}$ positive with/without MMR expression and BRCA1 negative with MMR expression. ${ }^{\mathrm{b}} \mathrm{P}<0.05$, derived from paired two-tailed Student's t-test or Mann-Whitney U test. MMR, mismatch repair; dMMR, MMR deficient; pMMR, MMR proficient; CDX2, caudal-type homeobox protein 2; miR, microRNA; NS, not significant.

results of the present study are consistent with observations found in previous studies $(30,31)$.

CDX2, a nuclear transcription factor implicated in CRC prognosis, was also found to be lowly expressed (56\%) in MMR deficient tumours and a higher proportion of CDX2 negative tumours was right-sided. While some reports (32) have shown similar presence of CDX2 positivity in $50 \%$ of dMMR tumours, other reports indicated that the low/loss of CDX2 expression was significantly associated with MMR deficiency and with right-sided tumours $(10,33)$.

With the advent of therapeutics that can target tumours with BRCA1/2 mutations, CRC tumours are also investigated for mutations in these genes. Although MMR and BRCA1 status is investigated independently, their combined loss has been reported in very few studies. A recent study (34) has shown that BRCA1 mutations are present in $1.1 \%$ of CRC tumours using next-generation sequencing on a 592-gene panel, which was the first study to show that BRCA1/2 mutations are more frequent in MSI high (MSI-H) tumours, and independently associated with higher tumour mutational burden. However, other studies have performed combined testing for BRCA1/2 mutational screening, along with MMR proteins, while screening for hereditary cancers (35). Other studies have reported IHC detection of BRCA1 in CRC $(12,13)$. A higher proportion of BRCA1 staining in these reports may be due to both cytoplasmic and nuclear staining being considered 
as positive. The present study considered nuclear presence in $>10 \%$ of cells as BRCA1 positive, which perhaps is the reason for the low BRCA1 positivity observed.

The tumours in the present study, with dual loss of BRCA1 and MMR, showed a high expression of miRs (miR-183-96-182 cluster) implicated in DDR, in addition to other aggressive features. This cluster is proven to be highly expressed in CRC tumours, promoting tumorigenesis, cancer progression and metastasis (36). These DDR miRs impair the homologous recombination mediated DNA repair by acting as negative regulators of the genes involved in the DDR pathway and may serve as predictive biomarkers for prognosis and potential therapeutic targets in CRC treatment (37). The present study, a retrospective CRC collected from pathology archives, has several limitations. A small sample size and TMA design restricting the evaluation of MMR proteins, which are known to be heterogenous in expression, may have an impact on the MMR and BRCA1 status. Moreover, although BRCA1 antibody (clone-MS110) is the most widely used, it has issues with specificity and sensitivity (38). While other studies have shown association of favourable prognostic factors, such as young age, well-differentiated tumours and low lymph node positivity with dMMR status, the present study observed a significant association with a higher lymph node positive status, which could be due to a higher proportion of stage III disease $(43 \%)$ in the present cohort. Although the present study showed that the incidence of MSI differs between stage II and stage III diseases, stage-specific analysis was not performed due to the small sample size. A lack of prognostic information on the present CRC series has limited ability of validating the effect of dual loss on clinical progression and requires validation in a larger series with a clinical outcome.

Newer modalities of treatment with immune checkpoint inhibitors are approved for treatment of colorectal cancers with MSI-H (6). However, the approval is limited to refractory mismatch deficient colorectal tumours in a metastatic setting (20). Although extensive efforts to explore additional combination therapies are ongoing, not all patients uniformly benefit from newer therapeutic modalities, which showcases the need to identify predictive biomarkers for a better selection of the patients (2). The present approach of using IHC-based markers to identify prognostic subtypes shows an easy, novel, and adaptable approach for subtyping colorectal cancer and should be further investigated in a larger series to confirm its relevance.

\section{Acknowledgements}

Not applicable.

\section{Funding}

This study was supported by the Department of Biotechnology (DBT), India (grant no. BT/MED/30/SP11263/2015).

\section{Availability of data and materials}

All data generated or analyzed during this study are included in this published article.

\section{Authors' contributions}

SR performed miRNA experiments and data analysis. ACE was involved in the construction of TMA, performing IHC and sample collection. MC reported the histological details of tumors. BJ identified the tumor blocks and collated clinical information. SS conceived and designed the study. JSP was involved in interpretation of all markers performing histological examination, analysis of data, conception and design of the study and drafting the manuscript. All authors read and approved the final manuscript.

\section{Ethics approval and consent to participate}

All procedures performed in this study involving human participants were in accordance with the ethical standards of the Institutional Ethical Committee, St John's Medical College and Hospital, Bangalore and approved by the same institute. Waiver of consent has been approved for this study since this was a retrospective study that was planned on specimens received for routine diagnostic purpose in the Department of Pathology, St John's Medical College and Hospital, Bangalore. All details of personal information regarding patients were blinded to the investigators. There was no direct contact between the researcher and participant.

\section{Patient consent for publication}

Not applicable.

\section{Competing interests}

The authors declare that they have no competing interests.

\section{References}

1. Ferlay J, Colombet M, Soerjomataram I, Mathers C, Parkin DM, Piñeros M, Znaor A and Bray F: Estimating the global cancer incidence and mortality in 2018: GLOBOCAN sources and methods. Int J Cancer 144: 1941-1953, 2019.

2. Hagan S, Orr MC and Doyle B: Targeted therapies in colorectal cancer-an integrative view by PPPM. EPMA J 4: 3, 2013.

3. Kocarnik JM, Shiovitz S and Phipps AI: Molecular phenotypes of colorectal cancer and potential clinical applications. Gastroenterol Rep (Oxf) 3: 269-276, 2015.

4. Kerr DJ and Midgley R: Defective mismatch repair in colon cancer: A prognostic or predictive biomarker? J Clin Oncol 28: 3210-3212, 2010.

5. Nojadeh JN, Behrouz Sharif S and Sakhinia E: Microsatellite instability in colorectal cancer. Excli J 17: 159-168, 2018.

6. Le DT, Uram JN, Wang H, Bartlett BR, Kemberling H, Eyring AD, Skora AD, Luber BS, Azad NS, Laheru D, et al: PD-1 blockade in tumors with mismatch-repair deficiency. N Engl J Med 372: 2509-2520, 2015.

7. Guinney J, Dienstmann R, Wang X, de Reyniès A, Schlicker A, Soneson C, Marisa L, Roepman P, Nyamundanda G, Angelino P, et al: The consensus molecular subtypes of colorectal cancer. Nat Med 21: 1350-1356, 2015.

8. Lenz HJ, Ou FS, Venook AP, Hochster HS, Niedzwiecki D, Goldberg RM, Mayer RJ, Bertagnolli MM, Blanke CD, Zemla T, et al: Impact of consensus molecular subtype on survival in patients with metastatic colorectal cancer: Results From CALGB/SWOG 80405 (Alliance). J Clin Oncol 37: 1876-1885, 2019.

9. Ragulan C, Eason K, Fontana E, Nyamundanda G, Tarazona N, Patil Y, Poudel P, Lawlor RT, Del Rio M, Koo SL, et al: Analytical validation of multiplex biomarker assay to stratify colorectal cancer into molecular subtypes. Sci Rep 9: 7665, 2019. 
10. Tóth C, Sükösd F, Valicsek E, Herpel E, Schirmacher P and Tiszlavicz L: Loss of CDX2 gene expression is associated with DNA repair proteins and is a crucial member of the Wnt signaling pathway in liver metastasis of colorectal cancer. Oncol Lett 15: 3586-3593, 2018.

11. Olsen J, Eiholm S, Kirkeby LT, Espersen ML, Jess P, Gögenür I, Olsen J and Troelsen JT: CDX2 downregulation is associated with poor differentiation and MMR deficiency in colon cancer. Exp Mol Pathol 100: 59-66, 2016.

12. Grabsch H, Dattani M, Barker L, Maughan N, Maude K, Hansen O, Gabbert HE, Quirke P and Mueller W: Expression of DNA double-strand break repair proteins ATM and BRCA1 predicts survival in colorectal cancer. Clin Cancer Res 12: 1494-1500, 2006.

13. Wang GH, Zhao CM, Huang $\mathrm{Y}$, Wang $\mathrm{W}$, Zhang $\mathrm{S}$ and Wang $\mathrm{X}$ BRCA1 and BRCA2 expression patterns and prognostic significance in digestive system cancers. Hum Pathol 71: 135-144, 2018.

14. Krajewska M, Fehrmann RS, de Vries EG and van Vugt MA: Regulators of homologous recombination repair as novel targets for cancer treatment. Front Genet 6: 96, 2015.

15. Petrovic N, Davidovic R, Bajic V, Obradovic M and Isenovic RE: MicroRNA in breast cancer: The association with BRCA1/2. Cancer Biomark 19: 119-128, 2017.

16. Wang Y, Huang JW, Calses P, Kemp CJ and Taniguchi T: miR-96 downregulates REV1 and RAD51 to promote cellular sensitivity to cisplatin and PARP inhibition. Cancer Res 72: 4037-4046, 2012.

17. Moskwa P, Buffa FM, Pan Y, Panchakshari R, Gottipati P, Muschel RJ, Beech J, Kulshrestha R, Abdelmohsen K, Weinstock DM, et al: miR-182-mediated downregulation of BRCA1 impacts DNA repair and sensitivity to PARP inhibitors. Mol Cell 41: 210-220, 2011.

18. Wahner Hendrickson AE, Menefee ME, Hartmann LC, Long HJ, Northfelt DW, Reid JM, Boakye-Agyeman F, Kayode O, Flatten KS, Harrell MI, et al: A Phase I Clinical Trial of the Poly(ADP-ribose) polymerase inhibitor veliparib and weekly topotecan in patients with solid tumors. Clin Cancer Res 24 744-752, 2018.

19. Svensson MC, Warfvinge CF, Fristedt R, Hedner C, Borg D, Eberhard J, Micke P, Nodin B, Leandersson K and Jirström K: The integrative clinical impact of tumor-infiltrating $\mathrm{T}$ lymphocytes and NK cells in relation to B lymphocyte and plasma cell density in esophageal and gastric adenocarcinoma. Oncotarget 8 : 72108-72126, 2017.

20. Byrne M and Saif MW: Selecting treatment options in refractory metastatic colorectal cancer. Onco Targets Ther 12: 2271-2278, 2019.

21. Nayak SS, Roy P, Arora N, Arun I, Roy MK, Banerjee S, Mallick I and Mallath MK: Prevalence estimation of microsatellite instability in colorectal cancers using tissue microarray based methods-A tertiary care center experience. Indian J Pathol Microbiol 61: 520-525, 2018.

22. Mazières J, Brugger W, Cappuzzo F, Middel P, Frosch A, Bara I, Klingelschmitt $\mathrm{G}$ and Klughammer B: Evaluation of EGFR protein expression by immunohistochemistry using $\mathrm{H}$-score and the magnification rule: Re-analysis of the SATURN study. Lung Cancer 82: 231-237, 2013

23. Bartley AN, Hamilton SR, Alsabeh R, Ambinder EP, Berman M, Collins E, Fitzgibbons PL, Gress DM, Nowak JA, Samowitz WS, et al: Members of the Cancer Biomarker Reporting Workgroup, College of American Pathologists. Template for reporting results of biomarker testing of specimens from patients with carcinoma of the colon and rectum. Arch Pathol Lab Med 138: 166-70, 2014.
24. Jørgensen AS, Rasmussen AM, Andersen NKM, Andersen SK, Emborg J, Røge R and Østergaard LR: Using cell nuclei features to detect colon cancer tissue in hematoxylin and eosin stained slides. Cytometry A 91: 785-793, 2017.

25. Korlimarla A, Prabhu JS, Anupama CE, Remacle J, Wahi K and Sridhar TS: Separate quality-control measures are necessary for estimation of RNA and methylated DNA from formalin-fixed, paraffin-embedded specimens by quantitative PCR. J Mol Diagn 16: 253-260, 2014.

26. Korlimarla A, Prabhu JS, Remacle J, Rajarajan S, Raja U, C E A, Srinath BS, Manjunath S, K S G, Correa M, et al: Identification of BRCA1 deficiency using multi-analyte estimation of BRCA1 and its repressors in FFPE tumor samples from patients with triple negative breast cancer. PLoS One 11: e0153113, 2016.

27. Ryan E, Sheahan K, Creavin B, Mohan HM and Winter DC: The current value of determining the mismatch repair status of colorectal cancer: A rationale for routine testing. Crit Rev Oncol Hematol 116: 38-57, 2017.

28. Boland CR and Goel A: Microsatellite instability in colorectal cancer. Gastroenterology 138: 2073-2087.e3, 2010.

29. Kumar A, Jain M, Yadav A, Kumari N and Krishnani N: Pattern of mismatch repair protein loss and its clinicopathological correlation in colorectal cancer in North India. S Afr J Surg 56: 25-29, 2018.

30. Chen W, Swanson BJ and Frankel WL: Molecular genetics of microsatellite-unstable colorectal cancer for pathologists. Diagn Pathol 12: 24, 2017.

31. Öhrling K, Edler D, Hallström M and Ragnhammar P: Mismatch repair protein expression is an independent prognostic factor in sporadic colorectal cancer. Acta Oncol 49: 797-804, 2010.

32. Neumann J, Heinemann V, Engel J, Kirchner T and Stintzing S: The prognostic impact of CDX2 correlates with the underlying mismatch repair status and BRAF mutational status but not with distant metastasis in colorectal cancer. Virchows Arch 473: 199-207, 2018

33. Baba Y, Nosho K, Shima K, Freed E, Irahara N, Philips J, Meyerhardt JA, Hornick JL, Shivdasani RA, Fuchs CS, et al: Relationship of CDX2 loss with molecular features and prognosis in colorectal cancer. Clin Cancer Res 15: 4665-4673, 2009.

34. Naseem M, Xiu J, Salem ME, Goldberg RM, Vanderwalde AM, Grothey A, Philip PA, Seeber A, Puccini A, Tokunaga R, et al: Characteristics of colorectal cancer (CRC) patients with BRCA1 and BRCA2 mutations. J Clin Oncol 37 (Suppl 4): S606-S606, 2019.

35. FeliubadalóL,López-Fernández A,Pineda M,Díez O, Del Valle J, Gutiérrez-Enríquez S, Teulé A, González S, Stjepanovic N, Salinas M, et al: Opportunistic testing of BRCA1, BRCA2 and mismatch repair genes improves the yield of phenotype driven hereditary cancer gene panels. Int J Cancer 145: 2682-2691, 2019.

36. Ma Y, Liang AJ, Fan YP, Huang YR, Zhao XM, Sun Y and Chen XF: Dysregulation and functional roles of miR-183-96-182 cluster in cancer cell proliferation, invasion and metastasis. Oncotarget 7: 42805-42825, 2016.

37. Dambal S, Shah M, Mihelich B and Nonn L: The microRNA-183 cluster: The family that plays together stays together. Nucleic Acids Res 43: 7173-7188, 2015.

38. Milner R, Wombwell H, Eckersley S, Barnes D, Warwicker J, Van Dorp E, Rowlinson R, Dearden S, Hughes G, Harbron C, et al: Validation of the BRCA1 antibody MS110 and the utility of BRCA1 as a patient selection biomarker in immunohistochemical analysis of breast and ovarian tumours. Virchows Arch 462: 269-279, 2013.

This work is licensed under a Creative Commons Attribution-NonCommercial-NoDerivatives 4.0 International (CC BY-NC-ND 4.0) License. 